\title{
QUALIDADE DE ÁGUA E DIAGNÓSTICO SOCIOAMBIENTAL DAS FAMÍLIAS DO ASSENTAMENTO FLORESTAN FERNANDES
}

\author{
Francielle Rodrigues de Oliveira \\ Universidade Federal do Espírito Santo, Programa de Pós-Graduação em Ciências Florestais, Jerônimo \\ Monteiro, ES, Brasil \\ francielle.loyal@gmail.com \\ Roberto Avelino Cecílio \\ Universidade Federal do Espírito Santo, Departamento de Ciências Florestais e da Madeira, Centro de \\ Ciências Agrárias e Engenharias, Jerônimo Monteiro, ES, Brasil \\ racecilio@yahoo.com.br \\ Sidney Sara Zanetti \\ Universidade Federal do Espírito Santo, Departamento de Ciências Florestais e da Madeira, Centro de \\ Ciências Agrárias e Engenharias, Jerônimo Monteiro, ES, Brasil \\ sszanetti@yahoo.com.br \\ Fabrina Teixeira Ferraz \\ Universidade Federal de Lavras, Programa de Pós-Graduação em Engenharia Florestal, \\ Lavras, MG, Brasil \\ fabrina.ferraz@hotmail.com
}

\begin{abstract}
RESUMO
O uso inadequado da terra e de agroquímicos, as atividades agropecuárias e o desmatamento afetam negativamente qualidade da água. As nascentes representam a principal fonte para atender às demandas de água no Assentamento Florestan Fernandes (AFF), localizado no Sul do Espírito Santo. Objetivando conhecer os entraves constituintes da complexa realidade de escassez de água, este trabalho realizou uma pesquisa de campo com oito famílias do assentamento para construir um diagnóstico socioambiental, identificar a percepção das famílias sobre o meio em que vivem e problematizar questões sobre o uso e ocupação da terra e suas interferências na disponibilidade de água potável e preservação de nascentes. Foram aplicados questionários para oito famílias que fazem uso da água de nascentes e para determinar a qualidade ambiental da água, utilizou-se o Índice de Qualidade da Água (IQA). Os resultados mostraram que a principal atividade do AFF é a agrícola. A queima do lixo doméstico, o uso de fossas negras e excremento animal podem contribuir para a degradação da água das nascentes. A maioria das famílias usa algum meio para desinfecção da água. O IQA classificou sete nascentes com qualidade boa e uma razoável.
\end{abstract}

Palavras-chave: Recursos hídricos. IQA. Saneamento rural. Uso e ocupação da terra. Espírito Santo.

\section{WATER QUALITY AND SOCIO-ENVIRONMENTAL DIAGNOSIS OF THE FAMILIES OF THE FLORESTAN FERNANDES SETTLEMENT}

\begin{abstract}
Inadequate use of land and agrochemicals, agricultural activities and deforestation negatively affect water quality. The springs represent the main source to meet the water demands in the Florestan Fernandes Settlement - AFF, located in the south of Espírito Santo. Aiming to know the constituent problems of the complex reality of water scarcity, this work carried out a field research with eight families of the settlement in order to construct a socio-environmental diagnosis, identify the perception of families about the environment in which they live and problematize questions about their use and land occupation and its interference with the availability of drinking water and spring preservation. Questionnaires were applied to 08 families that use spring water and to determine the environmental quality of water, we used the Water Quality Index (WQI). The results showed that AFF's main activity is agricultural. Burning domestic waste, the use of black pits and animal excrement
\end{abstract}


can all contribute to the degradation of spring water. Most families use some means for disinfecting water. The classified seven springs with good quality and one reasonable.

Keywords: Water resources. WQI. Rural sanitation. Land use and occupation. Espírito Santo.

\section{INTRODUÇÃO}

A água apesar de consistir em um recurso natural renovável é limitada. Dessa forma, seu uso racional e sua conservação são essenciais para a sustentabilidade. $\mathrm{Na}$ área rural, a retirada da vegetação, as atividades agropecuárias e o uso inadequado do solo podem degradar as nascentes e corpos hídricos, sendo que isso interfere na qualidade e quantidade de água produzida numa bacia hidrográfica (KOBIYMA et al., 2008). O superpastejo de bovinos, por exemplo, pode resultar em compactação do solo, comprometendo o processo de infiltração de água da chuva no terreno (DAVIDE et al., 2000), como também pode poluir a água, já que as fezes de animais podem conter quantidade elevada de microorganismos (MASTERS et al., 2011). Além disso, a irrigação inadequada, o preparo impróprio e a cobertura insuficiente do solo são fatores que geralmente influenciam na degradação ambiental. Desse modo, proteger e conservar as áreas de nascentes possibilita o ressurgimento das espécies nativas, aumento natural de vazão dos cursos d'água, novo habitat para a fauna e a valorização das áreas restauradas (BOMFIM et al., 2015).

A degradação de corpos hídricos é um problema antigo e impossibilita a utilização deste recurso para as atividades mais restritivas, como o abastecimento humano, a dessedentação de animais, a produção de alimentos ou a pesca. O resultado da indisponibilidade de água em quantidade e, ou, em qualidade, pode chegar a interferências na saúde pública, com deterioração da qualidade de vida e do desenvolvimento econômico e social (TUNDISI, 2008). Em comunidades rurais, onde não há disponibilidade de águas em rios ou reservatórios, e devido à inexistência de abastecimento de água pelo sistema convencional público, fica para as nascentes a importante função no suprimento de água para uso doméstico, agricultura e pecuária. A água das nascentes comumente é considerada como potável, e é bastante utilizada sem qualquer tratamento prévio. Todavia, essa associação das nascentes com ambientes naturais intocados não se confirma e, por isso, conhecer suas particularidades tipológicas e pedológicas auxilia o estudo do seu grau de vulnerabilidade (FELIPPE E MAGALHÃES JUNIOR, 2012) e pureza.

Dentre as localidades rurais, os assentamentos da Reforma Agrária frequentemente contêm expressivo passivo ambiental, herança da forma de ocupação destas áreas e do modelo agrícola implantado nas antigas fazendas, que em muitos casos desconsideravam a capacidade de uso e ocupação dos solos e dos recursos naturais (MARCATTI, 2014). A situação ambiental é constituída basicamente de pastagens, extensas áreas de monoculturas, muitas vezes abandonadas, e áreas de vegetação nativa degradadas. Além disso, é comum casos de assoreamento de rios e contaminação dos corpos d'água (CAPOANE et al., 2012). Semelhante a esse cenário, tem-se o Assentamento Florestan Fernandes, localizado no sul do estado do Espírito Santo, que apresenta problemas com escassez de água potável, com consequente ameaça à segurança alimentar, sustentabilidade econômica, qualidade de vida e à saúde das famílias residentes.

A qualidade da água é definida pelas suas características químicas, físicas e biológicas, refletindo as condições naturais e do uso e manejo do solo (MAROTTA et al., 2008; SOUZA, 2011). Estas características são, portanto, necessárias para obter um panorama da situação dos corpos hídricos no que diz respeito aos impactos antrópicos na bacia hidrográfica e para que medidas de controle sejam executadas (SANTOS, 2016). Para o público em geral, as informações dos valores de concentrações dos poluentes nos corpos d'água podem ser de difícil interpretação (SPERLING, 2005), motivo pelo qual são selecionados os parâmetros mais representativos, expressos por valores adequados a índices de qualidades, que podem viabilizar o monitoramento dos mananciais, como por exemplo, o Índice de Qualidade da Água - IQA. Visto que a qualidade da água é reflexo 
da manutenção adequada dos corpos hídricos, é possível inferir que os impactos ambientais perpassam por questões sociais, econômicas e culturais, e ocorrem a partir de diferentes atividades humanas (GONÇALVES, 2013). De fato, o produtor rural, ao explorar os recursos naturais para produção de alimentos, criação de animais e abastecimento de água, que pode causar um desequilíbrio no meio ambiente e, quando de forma desordenada, infringe a legislação ambiental podendo colocar em risco a garantia de uso futuro. Assim, estudar e compreender as modificações causadas pelo homem, possibilita evitar ou minimizar, bem como estabelecer um convívio mais harmonioso entre o produtor rural e o meio em que vive, dando mais condições de desenvolver suas atividades agropecuárias de forma a mitigar os impactos aos elementos da paisagem (MANOEL E CARVALHO, 2013).

Os recursos existentes na propriedade, se usados indevidamente e de maneira irracional, ao contrário do que se espera produzir a partir deles - geração de emprego e renda, qualidade de vida e bem-estar social - passa a contribuir para a redução da produtividade agrícola e aumenta os riscos relacionados a perdas econômicas e ambientais. Nesse contexto, torna-se evidente a necessidade de considerar as interações entre os setores social, econômico e ambiental, a fim de conduzir estratégias de uma agricultura sustentável (SANTOS et al., 2007), visando a segurança alimentar, a dignidade do trabalhador rural e o manejo planejado dos recursos naturais. Consequentemente, isso perpassa a fronteira do eco-desenvolvimento, atendendo, inclusive, à função social da propriedade rural (FELKER et al., 2013).

Diante do exposto, observando a relevância das nascentes e a disponibilidade de água em quantidade e qualidade para consumo humano e desenvolvimento de atividades econômicas rurais no AFF, assim como a carência de informações acerca dos aspectos sociais, econômicos e ambientais do assentamento, espera-se conhecer sobre a qualidade da água das nascentes do assentamento e tem-se a seguinte hipótese: Existe uma forte relação que interfere diretamente nas condições hídricas das nascentes em decorrência do uso que é feito na sua área de contribuição.

\section{METODOLOGIA}

Para testar a hipótese que norteia esse trabalho, realizou-se um estudo no referido assentamento rural, dividido em duas etapas: A aplicação de um questionário para conhecer a realidade socioambiental das famílias e, posteriormente amostragens periódicas e análises laboratoriais para avaliar os parâmetros físicos, químicos e microbiológicos da água, bem como o cálculo do IQA das nascentes.

\section{ÁREA DE ESTUDO}

O Assentamento Florestan Fernandes situa-se entre os municípios de Guaçuí e São José do Calçado, região Sul do estado do Espírito Santo, pertencente à bacia do rio Itabapoana (Figura 1). A cobertura vegetal natural na região Sul Capixaba se classifica como Floresta Estacional Semidecidual (INCAPER, 2011). A temperatura média anual varia entre 20 a $22^{\circ} \mathrm{C}$, as precipitações mais intensas ocorrem nos meses de outubro a abril, com uma média anual acumulada entre 1400 a $1450 \mathrm{~mm}$; o inverno é seco, influenciado pela altitude da região que varia de 600 a $800 \mathrm{~m}$ (PEZZOPANE et al., 2012). O clima é do tipo Cfa de acordo com a classificação de Köppen.

O AFF possui cerca de 30 nascentes e, deste total, foram selecionadas oito para constituir os tratamentos a serem estudados. Dentre elas, cinco nascentes estão inseridas no Programa de Manutenção e Recuperação de Nascentes, ao qual receberam o cercamento e plantio de mudas, e outras três nascentes que ainda não possuem cercamento e continuam sem vegetação e com acesso de pessoas e animais. Devido à distância entre as nascentes e a dificuldade de acesso, além da morosidade e complexidade das análises laboratoriais, não foi possível um maior número de nascentes estudadas.

$\begin{array}{lllll}\text { Caminhos de Geografia } \quad \text { Uberlândia-MG } & \text { v. 21, n. } 74 & \text { Abr/2020 } & \text { p. 226-240 Página } 228\end{array}$


Figura 1 - Área de estudo e localização das nascentes selecionadas.

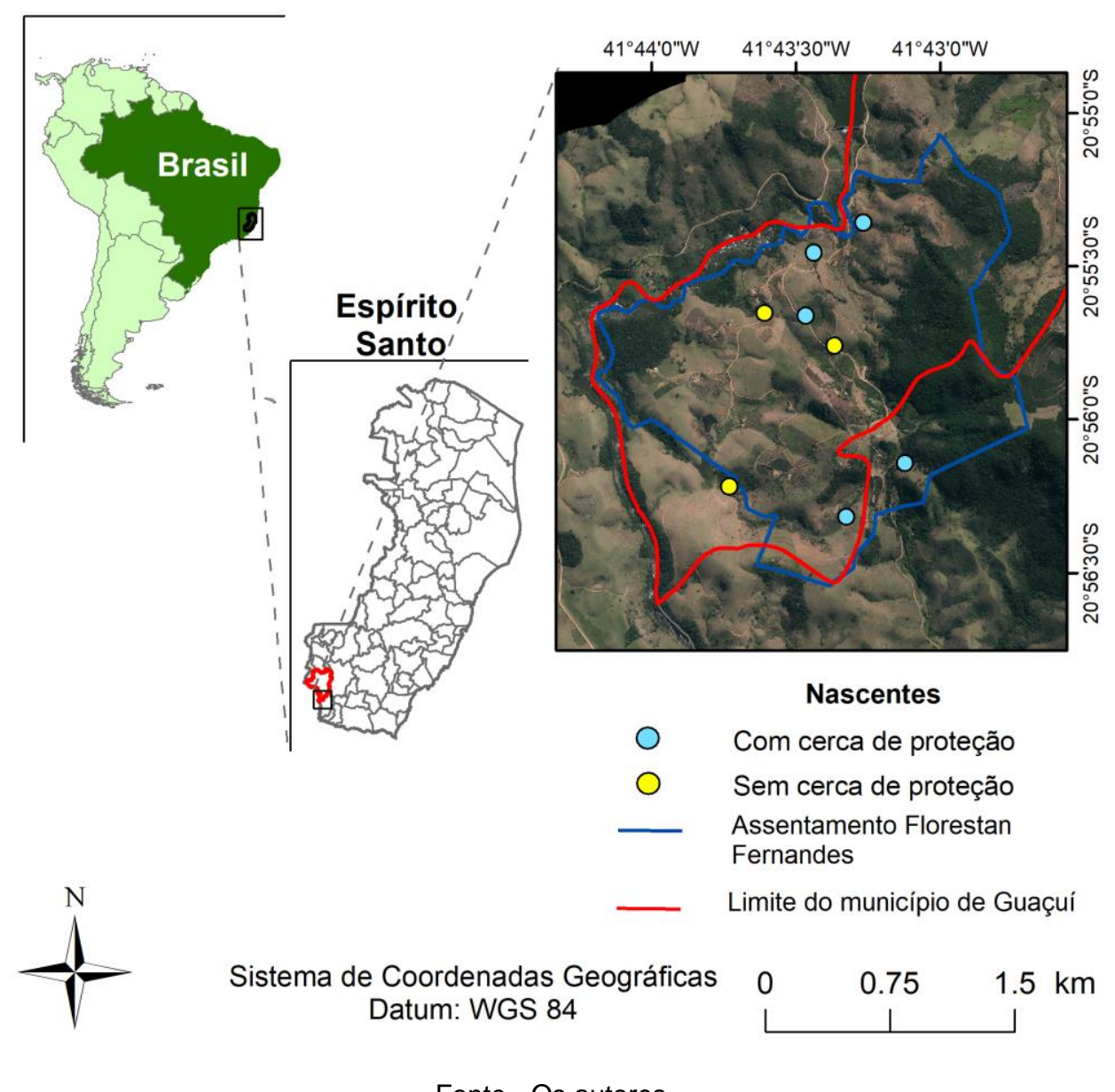

Fonte - Os autores.

\section{APLICAÇÃO DE QUESTIONÁRIOS E DIAGNÓSTICO SOCIOAMBIENTAL}

Utilizou-se uma pesquisa de campo com aplicação de questionário semiaberto elaborado por perguntas pré-estruturadas. O questionário desempenhou apenas a função de roteiro para conduzir as entrevistas, visando facilitar a participação dos produtores rurais e estimular a espontaneidade das informações (SANTOS et al., 2007). As questões compreendem temas de relevância social e ambiental com o objetivo de reunir informações sobre as áreas cultivadas, os principais cultivos, criação de animais, tamanho das famílias, escolaridade, entre outros. Foram abordados, ainda, possíveis problemas ambientais nas propriedades; o uso do solo e destinação de resíduos, principalmente próximos das nascentes; fontes pontuais de poluição por esgotos; utilização de agroquímicos; uso da água da nascente e a percepção dos proprietários quanto aos problemas de degradação ambiental. Os questionários foram elaborados e adaptados conforme trabalhos semelhantes de Schimitz (2017) e Manoel e Carvalho (2013). A pesquisa e o questionário foram avaliados e aprovados pelo Comitê de Ética em Pesquisa com Seres Humanos do Campus de Alegre da Universidade Federal do Espírito Santo (CEP/Alegre/UFES) conforme determina a Resolução CNS 466/12, do Conselho Nacional de Saúde do Ministério da Saúde (CNS/MS).

A entrevista foi realizada no próprio Assentamento e selecionaram-se para estudos as famílias as quais as análises da água das nascentes tenham sido realizadas, com o propósito de ter parâmetros que permitissem comparação. Ao final das entrevistas as informações foram analisadas primeiramente de forma individual, na tentativa de estabelecer uma relação entre as condições socioeconômicas e ambientais da propriedade com os resultados das análises de qualidade da água das respectivas nascentes e posteriormente de forma conjunta, a fim de construir um panorama geral das condições higiênicas e sanitárias no uso da água no AFF. 


\section{ANÁLISES E ÍNDICE DE QUALIDADE DE ÁGUA (IQA)}

Foram realizadas quatro campanhas de campo e as amostragens aconteceram entre o mês de março de 2017 a outubro de 2017, sempre pela manhã e em dias sem chuva, obedecendo o limite mínimo de 48 horas após o evento de precipitação. As coletas foram planejadas de forma a acompanhar a tendência da qualidade da água durante $o$ ano. Os procedimentos de amostragem seguiram as normas conforme Guia Nacional de Coleta e Preservação de Amostras (CETESB, 2011). Foram analisados os nove parâmetros que compõe o IQA adaptado pela Companhia Ambiental do Estado de São Paulo - CETESB (coliformes termotolerantes, Demanda Bioquímica de Oxigênio - DBO, fósforo total, nitrogênio total, oxigênio dissolvido, $\mathrm{pH}$, sólidos totais temperatura e turbidez). À exceção da temperatura e oxigênio dissolvido que foram medidos em campo, os demais parâmetros foram analisados em laboratório de acordo com os métodos analíticos do Standard Methods for Examination of Water and Wastewater (APHA; AWWA; WEF, 2012).

Para cada uma das quatro amostragens, utilizaram-se dois frascos de polietileno de $500 \mathrm{ml}$ para cada nascente, somando 1 litro de água amostral, para atender as análises laboratoriais. Os frascos para análise de coliformes foram submetidos à esterilizações prévias com água quente e, para as demais análises, realizou-se a ambientação com uma tríplice lavagem com a própria água do local amostrado. Os frascos foram mergulhados na água com o orifício para baixo e contra o fluxo, deixando um pequeno espaço incompleto para proceder a homogeneização no início das análises. Para preservar as amostras até a chegada ao laboratório, após cada coleta, estas foram acondicionadas imediatamente em uma caixa térmica com gelo.

A determinação do IQA seguiu o proposto pela CETESB, utilizando os dados coletados com a caracterização microbiológica e físico-química das nascentes. O IQA-CETESB é calculado como um produtório das notas individuais (q) de cada variável, obtido em função de sua concentração na amostra, elevadas aos respectivos pesos (w), determinado segundo sua importância para a conformação global da qualidade da água, tendo como objetivo o seu uso para o abastecimento público (CETESB, 2012), como apresentado na Equação. Como resultado, têm-se valores que variam de 0 a 100 e assim, possibilitou o enquadramento das águas das nascentes analisadas em categorias para o consumo humano.

$$
I Q A=\prod_{i=1}^{n} q_{i}^{w_{i}}
$$

Em que:

IQA: Índice de Qualidade da Água (número entre 0 e 100);

П: produtório IQA;

qi:valor numérico associado a qualidade da i-ésima variável (número entre 0 e 100);

wi: peso correspondente a i-ésima variável (número entre 0 e 1);

i: número do parâmetro (número variando entre 1 a 9). 
Os pesos (wi) de cada parâmetro estão apresentados na Tabela 1:

Tabela 1 - Parâmetros e pesos relativos ao IQA.

\begin{tabular}{ccc}
\hline Parâmetro & Unidade & Pesos relativos \\
\hline Coliformes termotolerantes & NMP 100 ml & 0,15 \\
DH & - & 0,12 \\
Nitrogênio total & $\mathrm{mg} \mathrm{L}^{-1}$ & 0,10 \\
Fósforo total & $\mathrm{mg} \mathrm{L}^{-1}$ & 0,10 \\
$\mathrm{mg} \mathrm{L}^{-1}$ & 0,10 \\
Diferença de temperatura & $\mathrm{o}$ & 0,10 \\
Turbidez & $\mathrm{UNT}$ & 0,08 \\
Sólidos totais & mg L & 0,08 \\
OD & $\%$ de saturação & 0,17 \\
\hline
\end{tabular}

Fonte - CETESB (2012).

O resultado da "Equação" consiste em um valor de IQA que permite enquadrar a água analisada em categorias conforme a classificação na Tabela 2.

Tabela 2 - Classificação da qualidade da água com base no valor numérico do IQA.

\begin{tabular}{cc}
\hline IQA & Classificação \\
\hline 0 a 19 & Péssimo \\
20 a 36 & Ruim \\
37 a 51 & Aceitável \\
52 a 79 & Bom \\
80 a 100 & Ótimo \\
\hline \multicolumn{2}{r}{}
\end{tabular}

O IQA foi calculado pelo produto ponderado da qualidade da água correspondente aos parâmetros da Tabela 1, a partir dos resultados das amostragens.

\section{RESULTADOS E DISCUSSÃO \\ DIAGNÓSTICO SOCIOAMBIENTAL:}

As informações geradas a partir dos questionários foram analisadas de modo a estabelecer uma relação entre as condições socioambientais das propriedades e os resultados das análises de qualidade da água das respectivas nascentes. Além de demonstrar um panorama das condições higiênicas e sanitárias no uso da água no AFF.

A população amostrada constitui-se de oito famílias pertencentes ao Assentamento Florestan Fernandes, as quais consomem água diretamente de nascentes. A quantidade de pessoas e suas respectivas faixas etárias estão dispostas no Quadro 1.

Quadro 1 - Faixa etária da população amostrada.

\begin{tabular}{|l|c|}
\hline \multicolumn{1}{c|}{ Faixa etária } & No de pessoas \\
Criança & 06 \\
Adolescente/jovem & 05 \\
Adulto & 09 \\
Idoso & 01 \\
Não quiseram ou não souberam informar suas idades & 02 \\
TOTAL AMOSTRAL & $\mathbf{2 3}$ \\
\hline
\end{tabular}

Fonte - Os autores.

Constatou-se que 15 membros trabalham no assentamento com atividades relacionadas à agricultura ou à associação de moradores, sete membros são estudantes e apenas um trabalha na usina hidrelétrica próxima. Tratando-se do grau de escolaridade, a maioria da composição familiar dos entrevistados possui o nível fundamental incompleto (aproximadamente 69,6\%), os que

$\begin{array}{lllll}\text { Caminhos de Geografia } \quad \text { Uberlândia-MG } & \text { v. 21, n. } 74 & \text { Abr/2020 } & \text { p. 226-240 Página } 231\end{array}$


possuem nível médio completo somam $17,4 \%$, o percentual referente aos que nunca estudaram compreendeu $8,6 \%$ e nenhum assentado possui curso superior.

O tipo de atividade desenvolvida pelos assentados se enquadra no modelo da agricultura familiar, principalmente pelas características de diversidade produtiva; mão de obra composta predominantemente por membros da própria família; existência de pequenas propriedades, com tamanho máximo de 11 hectares; e pouco uso de insumos externos. Além da importância na economia local, a agricultura encarrega-se de gerar empregos.

Com relação à área da propriedade, o tamanho varia entre 1,7 a 11,0 hectares. Na caracterização quanto às atividades agrícolas, as propriedades apresentaram diversidade nos cultivos: olericultura, café, fruticultura (laranja, banana, cana, maracujá, goiaba, acerola, jabuticaba, entre outras menos expressivas), mandioca, milho, feijão, seringueira e pastagem. A produção é destinada à subsistência das famílias e geração de renda, além disso, usa-se a cana e o milho produzidos como complementação alimentar de animais. Apenas $50 \%$ dos entrevistados souberam informar a dimensão da área designada ao plantio, que varia de três a dez hectares. Para o desenvolvimento das culturas, metade dos agricultores usam adubo químico e pelo menos um tipo de agroquímico; $37,5 \%$ usam adubo orgânico, mesmo que em pequena quantidade; e $75 \%$ fazem calagem no solo. As embalagens vazias dos agroquímicos, segundo os entrevistados, são devolvidas na loja onde foram adquiridas. A criação de gado, equinos, suínos e aves, para produção de leite, carne, ovos, meio de trabalho e entretenimento são comuns no assentamento. Todas as famílias entrevistadas informaram possuir pelo menos um tipo de criação animal, sendo a mais significativa a criação de galinha caipira, seguida pela bovinocultura.

No que se refere ao saneamento ambiental, quando questionados sobre o destino de águas domésticas residuais, todos os proprietários responderam que são direcionadas às fossas rudimentares construídas desde o início da apropriação, há cerca de quatorze anos, e segundo as informações obtidas, as fossas nunca passaram por processo de manutenção preditiva ou corretiva . Quanto ao fim dado ao lixo seco produzido pela família, à exceção de um entrevistado que leva o lixo até a cidade mais próxima para ser recolhido, os demais participantes da pesquisa usam a queima. Para a eliminação dos resíduos orgânicos, sete dos oito assentados responderam que são convertidos em adubos para as plantações, a prática de enterrar é adotada por apenas um entrevistado. Já para os dejetos dos animais da propriedade, quatro participantes relataram usar o esterco como adubação orgânica, principalmente nas hortas, enquanto dois não utilizam os excrementos para nada, deixando-os sobre o solo. Outros dois não quiseram ou não souberam responder ao questionamento.

Segundo $75 \%$ dos entrevistados, a unidade familiar possui uma nascente que representa sua principal fonte de água. Os $25 \%$ restantes ressaltaram que embora exista nascente em suas propriedades, consomem água de outra nascente do loteamento vizinho. Numa média de 12 anos, apesar das famílias utilizarem a água das nascentes para as mais diversas finalidades, como beber, cozinhar, higiene pessoal e doméstica, irrigação, dessedentação de animais e atividades produtivas, nunca realizaram análises laboratoriais de potabilidade da água, porém foi observado interesse por parte de alguns assentados na realização.

Para armazenar e conseguir disponibilidade no uso da água, todos os participantes da pesquisa contam com caixa d'água como reservatórios, onde a água é captada e direcionada via gravidade por tubulação de PVC (policloreto de polivinila). A maioria (62,5\%) dos entrevistados faz a limpeza das caixas d'água; $37,5 \%$ usando o conjunto água + escova + hipoclorito de sódio, e $25 \%$ usam somente água e escova. As frequências de desinfecção variam entre 30 a 180 dias, porém 12,5\% não opinaram. Quanto a algum membro da família ter ficado doente por ingestão da água, relataram que nunca ocorreram problemas de saúde atribuídos ao consumo de água contaminada.

Nenhum assentado assumiu uso de adubos químicos e/ou agrotóxicos próximo a nascentes. Sobre uma possível alteração de sabor da água durante as chuvas, a resposta negativa também foi unânime. Quando perguntados se a água da nascente era suficiente para abastecer a família, sete responderam positivamente, em contrapartida todos os entrevistados foram categóricos em afirmar que as nascentes reduzem a quantidade de água em algum período do ano. Os principais problemas levantados pelos participantes foram: falta de água em determinado período do ano; distancia da casa à nascente; e dificuldade para captar a água da nascente. Embora apenas um assentado não tenha considerado a água de qualidade, $75 \%$ tratam a água por meio de filtragem 
diária, uso de hipoclorito de sódio a cada mês ou ambos os métodos simultaneamente, sendo $33,3 \%$ o percentual referente a cada método utilizado.

Este estudo contém características da realidade social, ambiental, econômica e higiênico-sanitária local, demonstrando as condições de vida da população assentada, comum também a outros assentamentos e comunidades rurais brasileiras, como descrito em trabalhos de Barcellos et al. (2006); Gonçalves (2013); Gonçalves e Gomes (2014) ; Marcatti (2014); Santos et al. (2007); e Schimitz (2017). Diante dos resultados obtidos com a aplicação dos questionários, pode-se inferir que as famílias residentes no AFF, em suas diversas atividades, exercem influência na conservação e manutenção das nascentes estudadas. Estão na comunidade há mais de 13 anos e utilizam a agricultura como principal fonte de renda.

Os dados dessa pesquisa apontam que de todos os componentes familiares maiores de idade, apenas um trabalha fora do assentamento. Percebe-se, então, que existe uma dependência social e econômica da agricultura pelos assentados e, portanto, faz-se necessário aliar o conhecimento e o esclarecimento sobre temas ligados às atividades desenvolvidas ao ambiente, objetivando contribuir para a percepção sobre impactos negativos pelo uso desordenado dos recursos naturais. Segundo Marcatti (2014), os sistemas de cultivo ou de uso de terras, que desconsideram a capacidade de suporte e sustentabilidade das áreas, podem levar os agroecossistemas a estágios de degradação irreversíveis.

Observou-se o uso da área no entorno das nascentes com as atividades agrícolas, caracterizando inconformidade com a normatização da Resolução no 303/02 do CONAMA (BRASIL, 2002), para as Áreas de Preservação Permanentes (APPs), que define para esta situação, 50 metros de diâmetro de raio para nascentes, cuja consequência é o impacto negativo na qualidade ambiental do manancial (DOURADO et al., 2009). Além da conservação da APP, a preocupação no cercamento das nascentes deve existir pois, esses sistemas vegetais são essenciais para o equilíbrio ambiental e devem representar uma atenção central para o desenvolvimento rural sustentável (CRISPIM et al., 2012). Todavia, as observações no AFF demonstraram semelhança ao trabalho de Felker et al. (2013), em que aproximadamente $37,5 \%$ dos entrevistados não utilizam práticas para proteção de suas vertentes. Dado a significativa ausência da vegetação que cumpre a função de filtro e barreira contra o carreamento de sedimentos para o curso d'água, destaca-se a possível poluição da água, resultante do transporte de partículas do solo, matéria orgânica, produtos químicos e de microrganismos patogênicos capazes de comprometes a potabilidade da água e oferecer riscos à saúde dos que a consomem (CALHEIROS, 2009; FELKER et al., 2013).

A escolaridade dos assentados entrevistados e de seus familiares não demonstrou correlação com a educação ambiental e sanitária encontrada, visto que há uma heterogeneidade nos níveis escolares e isso não foi suficiente para denotar diferença na condição ambiental das propriedades. Por outro lado, a quantidade de estudantes é expressiva e esse fato deve ser apontado como algo positivo a ser explorado dentro das escolas locais, a fim de aguçar nas crianças e jovens a percepção sobre o meio ambiente em que vivem e promover atividades de conservação, norteados pelos aspectos culturais, para aliar crescimento da economia, ecologia e os valores sociais.

Essas atividades devem ser desenvolvidas priorizando o manejo adequado dos recursos naturais existentes e medidas sanitárias preventivas, haja vista que as problemáticas relacionadas principalmente aos recursos hídricos perpassam a fronteira rural e afetam toda a sociedade e sua qualidade de vida. A educação ambiental, segundo Gonçalves (2013), é um importante meio de sensibilizar e envolver as comunidades de forma a não permitir a formação de conflitos diante de adequação nas mudanças e quebra de paradigmas.

O sistema sanitário de todas as residências são fossas rudimentares conhecidas também por "fossas negras". No Brasil, esse perfil para descarte de águas domésticas residuais e dejetos ainda é amplamente seguido nas zonas rurais, onde não há coleta e tratamento de esgoto (BERTONCINI, 2008). Essa instalação é a forma mais primitiva de saneamento e consiste basicamente de um buraco no terreno, coberto ou não, onde os resíduos caem diretamente no solo. Esse sistema possibilita que a água e dejetos depositados infiltrem e se dissipe, ocasionando contaminação do solo, lençol freático e, por conseguinte, a água (SILVA, 2014). Segundo Costa e Guilhoto (2014), as fossas rudimentares provocam poluição da água superficial e subterrânea, além de contribuir para a proliferação de vetores de doenças e ter odor desagradável.

Há, portanto, uma precariedade das condições de saneamento básico na área de estudo, cuja situação torna-se preocupante para a saúde da comunidade. Souza et al. (2016) concluíram que há

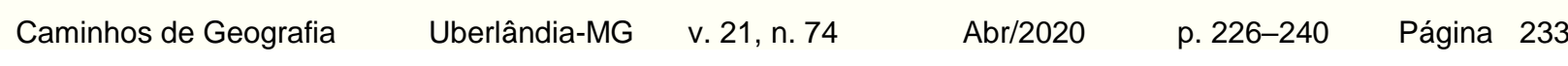


uma alta prevalência de enteroparasitoses como helminto Ascaris lumbricoides e os protozoários Entamoeba coli e Giardia duodenalis nos indivíduos residentes em um assentamento rural no estado do Piauí, reforçando a relação entre a falta de água tratada, fossas adequadas e rede de esgoto aos casos de parasitoses intestinais.

Para Visser et al. (2011) a solução para erradicação da incidência de parasitoses intestinais seria a melhoria das condições socioeconômicas, no saneamento básico e na educação em saúde, sendo todas essas esferas subsidiadas pelas mudanças em hábitos culturais. Vários fatores contribuem para a alteração da qualidade da água dos mananciais. A falta de saneamento rural é uma das principais causas de insalubridade e degradação hídrica, caracterizando-se pela disposição inadequada de resíduos sólidos e líquidos, demandando estudos acerca do tema para melhoria da qualidade de vida da população (CRISPIM et al., 2012).

No assentamento, assim como a maioria das áreas rurais, não há sistema de coleta de resíduos, ficando para os moradores a responsabilidade de destinação final dos mesmos. Logo, a queima do lixo seco torna-se o meio no qual os resíduos produzidos no AFF são eliminados, comprometendo ainda mais a integridade da água das nascentes. Simonato (2013), ao investigar a gestão dos resíduos sólidos em um assentamento rural em São Paulo, relata que a falta de um sistema de descarte consolidado e eficiente em inúmeras localidades rurais pode ocasionar sérios problemas ao ambiente, como a contaminação da água, do solo e até dos alimentos produzidos. Dados do IBGE (2013) apontam que em mais da metade dos domicílios brasileiros das zonas rurais a queima do lixo como alternativa cresceu em torno de 10 pontos percentuais, passando de 48,2\% em 2000 para $58,1 \%$ em 2010 . A queima e, ou a prática de enterrar os resíduos domésticos, podem gerar compostos como óxidos de enxofre, dioxinas e furanos.

Assim, é imprescindível serviço de coleta, tratamento ou disposição final adequada para o lixo, pois a inexistência desses contribuem para a contaminação dos solos, lençol freático e dos corpos hídricos, disseminação de doenças e poluição atmosférica pelo gás metano (VIEIRA et al., 2015). Ressalta-se que os restos do lixo queimado, quando não são deixados no local onde foi feito a queima, são enterrados tendo, portanto, outros desdobramentos poluidores (FRIESTINO et al., 2015). A produção de resíduos secos está ligada tanto à saúde pública, uma vez que faz parte do saneamento básico, quanto relaciona-se intimamente com a preservação e/ou conservação dos recursos naturais, principalmente no que tange aos mananciais hídricos, podendo ser por esse motivo considerado uma questão de cunho socioambiental.

Os resíduos orgânicos são destinados à compostagem pelos assentados que é comumente utilizado para adubação na agricultura, uma importante ferramenta de reaproveitamento dos resíduos sólidos orgânicos. Porém, o aproveitamento dos resíduos orgânicos domiciliares, como adubo para a produção agrícola, requer alguns conhecimentos que possibilitem a adequada forma de prepará-los, e que garantam um produto estabilizado e de boa qualidade, que forneça nutrientes e condicione o solo de forma adequada (CAMPANA LOUREIRO et al., 2007).

Ainda sobre os resíduos, quando questionados sobre o destino dado aos dejetos animais produzidos, a maioria dos participantes informou usar o esterco como adubação. Embora essa seja uma alternativa eficiente já consolidada capaz de reduzir a utilização de fertilizantes químicos nas culturas agrícolas, esses resíduos são ricos em matéria orgânica, em agentes patogênicos para bovinos e para humanos, e são ainda geradores de poluição das águas superficiais e subterrâneas, quando carreados pela ação das chuvas (DUARTE et al., 2008)É preciso atentar-se para o manejo e técnicas adequadas para que a adubação por meio de excremento animal cumpra sua função de aliado ambiental e não passe a ser um agravante para poluição do solo, água e produtos oriundos da olericultura, que é uma das principais fontes de renda para os assentados. Segundo trabalhos de Fernandes et al. (2015) a contaminação de hortaliças por microrganismos pode ser consequência predominantemente, além de outros fatores, da adubação orgânica oriunda de dejetos fecais de animais. Os demais assentados entrevistados não fazem uso dessa prática, deixando os excrementos sobre o solo onde foram despejados.

As famílias entrevistadas consideram a água de boa qualidade e a consomem há mais de treze anos sem a ocorrência de problemas de saúde evidentes. A água utilizada no assentamento nunca foi submetida a análises laboratoriais para verificação da sua potabilidade, a qual proporciona aos consumidores uma sensação de pureza. Além disso, a falta das análises aumenta as chances de escolhas equivocadas nos métodos e frequências de tratamento da água, e de higienização das caixas de armazenamento (AMARAL et al., 2003). Acredita-se que há um aumento na poluição da

$\begin{array}{lllll}\text { Caminhos de Geografia } \quad \text { Uberlândia-MG } & \text { v. 21, n. } 74 & \text { Abr/2020 } & \text { p. 226-240 Página } 234\end{array}$


água e que essa esteja ligada à ausência de limpeza periódica e adequada dos reservatórios, práticas realizadas por apenas $62,5 \%$ das propriedades estudadas.

Os principais processos de tratamento doméstico da água usados são a filtração e a desinfecção química usando o cloro, e embora a maioria das famílias use algum meio para desinfecção da água, ainda existem assentados que consomem a água in natura. Os principais contaminantes de água no meio rural consistem de argilas suspensas, matéria orgânica, patógenos originados de fossas, além de pesticidas e fertilizantes usados nas culturas agrícolas, aos quais podem ser eliminados por meio de processos de tratamento (BERTONCINI, 2008). O tratamento da água para o consumo humano tem a finalidade de torná-la segura do ponto de vista de potabilidade. São práticas acessíveis que visam melhorar suas características físicas, químicas e bacteriológicas. $\mathrm{O}$ simples uso de filtros caseiros de cerâmica auxilia na potabilidade, eliminando até $99 \%$ dos patógenos (COSTA SOBRINHO et al., 2016).

Os resultados da aplicação do questionário oportunizaram conhecer a realidade em que vivem as famílias do Florestan Fernandes, de modo a caracterizar a comunidade no que diz respeito às condições sociais e medidas de saneamento, as atividades impactantes desenvolvidas na área e a percepção ambiental dos mesmos. O diagnóstico da utilização da água e do conhecimento das pessoas nessas áreas sinaliza para os riscos à saúde dessas populações e da contaminação e poluição das nascentes (BARCELLOS et al., 2006).

\section{IQA DAS NASCENTES}

Os Índices de Qualidade de Água cumprem o dever de tradução dos resultados por serem facilmente compreendidos (SANTOS et al., 2017). Os resultados dos parâmetros obtidos após as análises laboratoriais das amostras embasaram o cálculo do IQA das nascentes.

Para obtenção dos dados relativos à qualidade da água, calculou-se a média entre as quatro campanhas, para cada ponto de amostragem sendo os resultados representados em tabela para apreciação e análise do comportamento. Os resultados médios das análises dos parâmetros nas quatro campanhas de amostragem, nas oito nascentes estão apresentados a seguir na Tabela 3.

Tabela 3 - Valores médios dos parâmetros analisados nas oito nascentes em estudo.

\begin{tabular}{|c|c|c|c|c|c|c|c|c|}
\hline Parâmetros & $\begin{array}{c}\text { Nascente } \\
01 \\
\end{array}$ & $\begin{array}{c}\text { Nascente } \\
02 \\
\end{array}$ & $\begin{array}{c}\text { Nascente } \\
03 \\
\end{array}$ & $\begin{array}{c}\text { Nascente } \\
04 \\
\end{array}$ & $\begin{array}{c}\text { Nascente } \\
05 \\
\end{array}$ & $\begin{array}{c}\text { Nascente } \\
06 \\
\end{array}$ & $\begin{array}{c}\text { Nascente } \\
07 \\
\end{array}$ & $\begin{array}{c}\text { Nascente } \\
08 \\
\end{array}$ \\
\hline $\mathrm{OD}\left(\mathrm{mg} \mathrm{L}^{-1}\right)$ & 8,20 & 3,63 & 3,87 & 4,23 & 3,21 & 6,02 & 3,53 & 4,67 \\
\hline Temperatura $\left({ }^{\circ} \mathrm{C}\right)$ & 21,25 & 27,15 & 24,93 & 24,10 & 24,68 & 24,30 & 28,95 & 29,68 \\
\hline $\mathrm{pH}$ & 7,14 & 6,01 & 5,94 & 6,14 & 6,02 & 6,39 & 5,29 & 6,59 \\
\hline $\mathrm{COL}_{\text {totais }}(\mathrm{NMP} / 100 \mathrm{~mL})$ & 3300,00 & 2840,00 & 2260,00 & 4340,00 & 2700,00 & 3900,00 & 1600,00 & 1340,00 \\
\hline $\mathrm{COL}_{\text {termo }}(\mathrm{NMP} / 100 \mathrm{~mL})$ & 240,00 & 380,00 & 880,00 & 360,00 & 80,00 & 20,00 & 40,00 & 180,00 \\
\hline $\mathrm{DBO}\left(\mathrm{mg} \mathrm{L}^{-1}\right)$ & 0,94 & 0,92 & 0,75 & 1,36 & 0,52 & 1,81 & 0,74 & 0,89 \\
\hline N Total $\left(\mathrm{mg} \mathrm{L}^{-1}\right)$ & 0,35 & 1,68 & 0,50 & 2,18 & 0,10 & 0,98 & 3,85 & 1,03 \\
\hline P Total (mg L $\left.{ }^{-1}\right)$ & 0,54 & 0,17 & 0,05 & 0,53 & 0,10 & 0,07 & 0,67 & 0,37 \\
\hline $\mathrm{Fe}\left(\mathrm{mg} \mathrm{L}^{-1}\right)$ & 0,10 & 1,68 & 2,56 & 1,11 & 0,13 & 0,78 & 0,26 & 0,28 \\
\hline $\mathrm{Ca}\left(\mathrm{mg} \mathrm{L}{ }^{-1} \mathrm{~L}\right)$ & 2,50 & 10,00 & 2,50 & 0,75 & 0,00 & 0,00 & 0,00 & 2,50 \\
\hline $\mathrm{Mg}(\mathrm{mg} \mathrm{L}-1 \mathrm{~L})$ & 1,25 & 2,50 & 5,00 & 2,50 & 0,00 & 1,25 & 1,25 & 1,25 \\
\hline Turbidez (UNT) & 3,83 & 19,44 & 8,03 & 26,83 & 11,27 & 12,32 & 2,72 & 1,84 \\
\hline $\mathrm{CE}(\mu \mathrm{S} / \mathrm{cm})$ & 38,23 & 25,94 & 24,52 & 64,58 & 49,70 & 46,78 & 75,45 & 75,38 \\
\hline Sólidos totais (mg L - ${ }^{-1} \mathrm{~L}$ ) & 51,50 & 170,50 & 64,5 & 234,50 & 53,65 & 106,00 & 62,25 & 35,50 \\
\hline Sólidos dissolvidos (mg L - ${ }^{-1} \mathrm{~L}$ ) & 47,00 & 92,00 & 34,00 & 42,50 & 43,00 & 66,25 & 34,00 & 66,75 \\
\hline Sólidos suspensos ( $\mathrm{mg} \mathrm{L}{ }^{-1} \mathrm{~L}$ ) & 4,00 & 78,50 & 30,50 & 192,00 & 21,00 & 39,75 & 28,25 & 23,25 \\
\hline
\end{tabular}

Notas: (1) Valores para nitrato, nitrito e nitrogênio amoniacal, respectivamente.

Com os resultados físico-químicos e microbiológicos obtidos, calculou-se o IQA para os pontos amostrados utilizando-se a média aritmética simples dos valores de cada parâmetro. A média dos valores das análises estão organizadas na Tabela 3.

Os valores do IQA-CETESB e as respectivas classificações quanto à qualidade da água para as nascentes estão expostos na Tabela 4. Os resultados do IQA encontrados na pesquisa variaram de

$\begin{array}{lllll}\text { Caminhos de Geografia } & \text { Uberlândia-MG } & \text { v. 21, n. } 74 & \text { Abr/2020 } & \text { p. 226-240 Página } 235\end{array}$


44,7 a 78,3. Verifica-se então que, com exceção da "Nascente 03", que apresentou qualidade "ACEITÁVEL", todas as demais nascentes tiveram sua qualidade classificada como "BOA". Os melhores índices foram alcançados pelos pontos de amostragem denominados "Nascentes 01 " e "Nascente 06", com valores de IQA 71,24 e 78,28, respectivamente:

Tabela 4 - Valores de IQA obtidos pelo método da CETESB nas nascentes estudadas.

\begin{tabular}{c|c|c|c}
\hline \multicolumn{1}{c}{ Nascente } & \multicolumn{1}{c}{ IQA } & Faixa de Variação & Classificação \\
\hline $\mathbf{0 1}$ & 71,24 & $52-79$ & BOA \\
$\mathbf{0 2}$ & 54,41 & $52-79$ & BOA \\
$\mathbf{0 3}$ & 44,73 & $37-51$ & ACEITÁVEL \\
$\mathbf{0 4}$ & 53,86 & $52-79$ & BOA \\
$\mathbf{0 5}$ & 60,98 & $52-79$ & BOA \\
$\mathbf{0 6}$ & 78,28 & $52-79$ & BOA \\
$\mathbf{0 7}$ & 57,18 & $52-79$ & BOA \\
$\mathbf{0 8}$ & 69,21 & $52-79$ & BOA \\
\hline
\end{tabular}

Embora as águas de sete nascentes tenham sido enquadradas como "BOA", os padrões normativos contrariaram essa classificação, posto que todas as nascentes apresentaram algum tipo de inconformidade com a Portaria de consolidação nำ/2017 (BRASIL, 2017) e a classe 2 da Resolução CONAMA № 357/05 (BRASIL, 2005), sobretudo para consumo humano. O panorama ambiental encontrado no AFF, principalmente no tocante à degradação da vegetação, sugere para as águas estudadas classificações diferentes destas apontadas no IQA-CETESB, no qual as nascentes foram indicadas como boa qualidade. Piasentin et al. (2009) analisarem a qualidade da água do Reservatório Tanque Grande, em São Paulo, utilizando o IQA-CETESB, seus resultados ultrapassaram os limites legais diversas vezes e mesmo assim obtiveram suas águas enquadradas principalmente na faixa "boa". Esse comportamento contraditório ocorreu devido à compensação gerada por outras variáveis que se enquadraram nos padrões legais.

Com efeito, os resultados de alguns parâmetros podem ter sido responsáveis por mascarar o valor do IQA, como por exemplo, pH e oxigênio dissolvido que consistem em dois dos parâmetros de maiores pesos do índice (qi). Isso porque devido às características intrínsecas das nascentes, que naturalmente possuem baixos teores de oxigênio dissolvido e pH ligeiramente ácidos, mesmo não implicando em comprometimento à saúde, foram consideradas fora dos padrões normativos de IQA. Abordagem semelhante a essa foi realizada por Agrizzi (2012), que entendeu que a proporção de $29 \%$ atribuída aos pesos dessas variáveis era muito elevada para dois parâmetros tidos como inadequados, classificando algumas nascentes erroneamente.

Por outro lado, apesar das condições ambientais nas quais algumas das nascentes estão inseridas, somente o fato de os resultados apontarem baixas concentrações de coliformes, pode ter sido o suficiente para superestimar a pontuação, como o ponto "Nascente 06 " com 20,00 NMP/100mL de E.coli e classificada como "BOA", embora com outras variáveis em desacordo. Já a "Nascente 03", com os piores resultados de coliformes termotolerantes $(880 \mathrm{NMP} / 100 \mathrm{~mL})$ foi enquadrada com a classificação "ACEITÁVEL", tendo a menor pontuação entre as demais. Porém, mesmo em pequenas concentrações, o Ministério da Saúde, por meio da Portaria de consolidação 꾸/2017, exige que os coliformes termotolerantes estejam ausentes na água para consumo, apontando incoerência com o índice. De fato, a nascente 01 poderia ter sido enquadrada como "BOA" por ter o maior número de parâmetros em atendimento às legislações, todavia as demais nascentes foram alocadas na mesma classe apesar de terem escores bem inferiores e divergentes com o Ministério da Saúde e CONAMA.

Lopes et al. (2008) acreditam que uma avaliação rigorosa da qualidade de corpos de águas não pode ficar restrita apenas aos resultados do IQA, uma vez que esse índice leva em consideração 
somente os parâmetros que podem afetar as propriedades organolépticas ${ }^{1}$, o equilíbrio ecológico e os riscos sanitários mais imediatos. Por isso, em relação à sua aplicabilidade, é pertinente o conhecimento sobre os destinos da água, prevendo seus usos múltiplos e suas características ambientais, pois assim identificam-se e selecionam-se os índices mais adequados para medir as variações qualitativas que se quer monitorar (BOLLMANN e MARQUES, 2000; GARDIMAN JUNIOR, 2012). Logo, deve-se atentar para que o índice seja aplicado para os fins aos quais ele foi criado, analisando-o detalhadamente e interpretando corretamente seus resultados. Para cada uso, deve-se usar padrões diferenciados, observando os parâmetros mais impactantes e adotando pesos individuais para uma mesma variável ambiental em cada condição.

Portanto, é preciso cautela no momento de transmitir os resultados do IQA ao público interessado, visto que trata-se simplesmente de uma maneira para facilitar a comunicação das condições ambientais dos corpos d'água e não um instrumento de avaliação de atendimento à legislação (SPERLING, 2005).

\section{CONSIDERAÇÕES FINAIS}

O Assentamento Florestan Fernandes tem sua realidade social e econômica fortemente atrelada ao meio agrícola, de forma que as famílias têm a agricultura como principal fonte de renda. Constatouse desconhecimento e despreparo para as práticas higiênico-sanitárias, observadas nas formas de destinação de lixo, usos de fossas rudimentares e tratamento prévio da água para utilização.

A inexistência de infraestruturas de saneamento básico e práticas higiênico-sanitárias, somadas à falta de estratégias de planejamento e gestão ambiental, resulta na ausência de manejo adequado do uso e ocupação da terra e, em consequência disso, da qualidade da água, interferindo na condição de vida da população usuária, posto que as famílias se encontram mais susceptíveis à contaminação por parasitoses intestinais. A qualidade da água foi aprovada na opinião dos participantes da pesquisa e concluiu-se que ainda prevalece o conceito de pureza em águas provenientes de nascentes.

As informações obtidas neste trabalho podem contribuir na ampliação dos conhecimentos a respeito da situação de preservação em que as nascentes se encontram, de tal forma que sirvam de alerta aos órgãos públicos e a comunidade local para uma maior conservação dos recursos hídricos e fornecer subsídios que sirvam de diretrizes para a elaboração futura de um plano de desenvolvimento ou aprimoramento das atividades agrícolas, de modo a manter a produtividade com o mínimo possível de impactos ambientais, viabilizando economicamente os agroecossistemas e minimizando a pressão sobre a área de contribuição das nascentes do assentamento.

As águas das nascentes calculadas por meio do IQA adaptado pela CETESB podem ser consideradas de qualidade "BOA", mas ressalta-se a necessidade de tratamento antes do consumo visto que sob as condições experimentais deste estudo, percebe-se que a utilização de agroquímicos, queima do lixo produzido, uso de fossas negras e excremento animal são fatores de impacto ambiental que podem contribuir para a degradação da água das nascentes de forma qualitativa e/ou quantitativa.

A partir do conjunto de informações apresentadas nesta pesquisa, conclui-se que o uso e ocupação do solo, bem como seu manejo interferem na qualidade da água, sobretudo para o abastecimento humano. Nesse cenário, apesar das águas provenientes das nascentes do Assentamento Florestan Fernandes serem consideradas de "BOA" qualidade pelos cálculos do IQA, o índice superestimou o nível qualitativo e contradiz o padrão exigido pelas normativas do CONAMA e Ministério da Saúde, já que alguns parâmetros se apresentam em condições incompatíveis com essas legislações. Dessa forma, cabe ressaltar que o IQA deve ser adotado como uma complementação às informações geradas pelas análises físicas, químicas e microbiológicas e em consonância com normas específicas.

\section{AGRADECIMENTOS}

O presente trabalho foi realizado com apoio da Coordenação de Aperfeiçoamento de Pessoal de Nível Superior - Brasil (CAPES) - Código de Financiamento 001.

1 São características de uma substância ou material que podem ser percebidas pelos sentidos humanos como a cor, o brilho, a luz, o odor, a textura, o som e o sabor

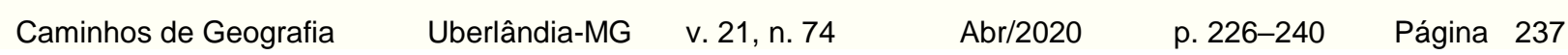




\section{REFERÊNCIAS}

AGRIZZI, D. V. Índice de qualidade da água de nascentes no Assentamento Paraíso, Alegre, ES. 2012.88f. Dissertação (Mestrado em Ciências Florestais) - Universidade Federal do Espírito Santo, Jerônimo Monteiro. 2012.

AMARAL, L. A. et al. Água de consumo humano como fator de risco à saúde em propriedades rurais. Revista de Saúde Publica, São Paulo, v. 37, n. 4, p. 510-514, 2003. https://doi.org/10.1590/S0034-89102003000400017

APHA - American Public Haealth Association ; AWWA - American Water Works Association-; WEF - Water Environment Federation. Standard Methods for the Examination of Water and Wastewater.Washington, DC, Estados Unidos: APHA/AWWA/WEF, 2012.

BARCELLOS, C. M. et al. Avaliação da qualidade da água e percepção higiênico-sanitária na área rural de Lavras, Minas Gerais, Brasil , 1999-2000. Cadernos de Saúde Pública, Rio de Janeiro, v. 22, n. 9, p. 1967-1978, 2006. https://doi.org/10.1590/S0102-311X2006000900028

BERTONCINI, E. I. Tratamento de efluentes e reúso da água no meio agrícola. Revista Tecnologia \& Inovação Agropecuária,São Paulo, v.1, n.1, p. 152-169, 2008.

BOLLMANN, H. A.; MARQUES, D. D. M. Bases para a estruturação de indicadores de qualidade de águas. RBRH - Revista Brasileira de Recursos Hídricos,Porto Alegre, v. 5, n. 1, p. 37-60, 2000. https://doi.org/10.21168/rbrh.v5n1.p37-60

BOMFIM, E. O. et al. Sustentabilidade hidroambiental de nascentes na bacia hidrográ ica do rio Gramame no Estado da Paraíba, Brasil. Sociedade \& Natureza, Uberlândia, v. 27, n. 3, p. 453-468, 2015. https://doi.org/10.1590/1982-451320150307

BRASIL. Ministério da Saúde. Portaria de Consolidação № 5, de 28 de setembro De 2017. Disponível em <http://portalarquivos2.saude.gov.br/images/pdf/2018/marco/29/PRC-5-Portariade-Consolida----o-n---5--de-28-de-setembro-de-2017.pdf >. Acesso em: 05 de dezembro de 2019.

BRASIL. Ministério do Meio Ambiente. CONAMA - Conselho Nacional do Meio Ambiente. Resolução n 357, de 17 de mar. de 2005. Dispõe sobre a classificação dos corpos de água e diretrizes ambientais para o seu enquadramento, bem como estabelece as condições e padrões de lançamento de efluentes, e dá outras providências. Diário Oficial da União [da] República Federativa do Brasil, Brasília, DF, 17 mar. 2005. Seção 1, p 58 - 63.

BRASIL. Ministério do Meio Ambiente. CONAMA - Conselho Nacional do Meio Ambiente. Resolução no 303, de 20 de março de 2002. Dispõe sobre parâmetros, definições e limites de Áreas de Preservação Permanente. Diário Oficial da União [da] República Federativa do Brasil, Brasília, DF, 13 mai. 2002. Seção 1, p 68.

CALHEIROS, R. de O. Cadernos da mata ciliar. 1. ed. São Paulo: Secretaria de Estado do Meio Ambiente, 2009.

CAMPANA LOUREIRO, D. et al. Compostagem e vermicompostagem de resíduos domiciliares com esterco bovino para a produção de insumo orgânico. Pesquisa Agropecuária Brasileira. Brasília, v. 42, n. 7, p. 1043-1048, 2007. https://doi.org/10.1590/S0100-204X2007000700018

CAPOANE, VIVIANE; SANTOS, D. R. DOS. Análise qualitativa do uso e ocupação da terra no assentamento Alvorada, Júlio de Castilhos - Rio Grande do Sul. Nera,Presidente Prudente v. 20, n. 2008, p. 193-205, 2012.

CETESB - Companhia Ambiental do Estado de São Paulo. Guia nacional de coleta e preservação de amostras: água, sedimento, comunidades aquáticas e efluentes líquidos /; Organizadores: Carlos Jesus Brandão ... [et al.]. -- São Paulo: CETESB; Brasília: ANA, 325p., 2011.

Significado Ambiental e Sanitário das Variáveis de Qualidade - Apêndice E. In: Relatório de Qualidade das Águas Superficiais do Estado de São Paulo 2011 [recurso eletrônico] / CETESB. - - São Paulo. 356 p.: il. color. - - (Série Relatórios / CETESB, ISSN 0103-4103) /; Organizadores: Carlos Eduardo Komatsu... [et al.]. 2012. Disponível em: $<$ https://cetesb.sp.gov.br/aguas-interiores/publicacoes-e-relatorios/> Acesso em: 20 de out.2019

COSTA, C. C. DA; GUILHOTO, J. J. M. Saneamento rural no Brasil: impacto da fossa séptica biodigestora. Engenharia Sanitaria e Ambiental, Rio de Janeiro, v. 19, n. spe, p. 51-60, 2014. https://doi.org/10.1590/S1413-41522014019010000171 
COSTA SOBRINHO, L. I. da.; COELHO, F. A. D. S.; COELHO, M. D. G. Eficácia de velas filtrantes na retenção de cistos de Giardia duodenalis em água experimentalmente contaminada. Ambiente e Agua - An Interdisciplinary Journal of Applied Science, Taubaté, v. 11, n. 2, p. 439, 15 abr. 2016.

CRISPIM, J. D. Q. et al. Conservação e proteção de nascentes por meio do solo cimento em pequenas propriedades agrícolas na bacia hidrográfica Rio do Campo no município de Campo Mourão - PR. Revista GEONORTE, Manaus, v. 3, n. 4, p. 781-790, 2012.

DAVIDE, A. C. et al. Restauração de matas ciliares - Informe Agropecuário. Belo Horizonte: Empresa de Pesquisa Agropecuária de Minas Gerais, 2000.

DOURADO, C. DA S. et al. Avaliação de impactos socioambientais na região da microbacia do Ribeirão do Machado em Cruz das Almas - BA. Revista Brasileira de Agroecologia, Dois Vizinhos, v. 4, n. 2, p. [S.I.], 2009.

DUARTE, E. R. et al. Análise da contaminação parasitária em compostos orgânicos produzidos com biossólidos de esgoto doméstico e resíduos agropecuários. Ciência Rural, Santa Maria, v. 38, n. 5, p. 1279-1285, 2008. https://doi.org/10.1590/S0103-84782008000500012

FELIPPE, M. F.; MAGALHÃES JUNIOR., A. P. M. Impactos ambientais macroscópicos e qualidade das águas em nascentes de parques municipais em Belo Horizonte, MG. Geografias, Belo Horizonte, v. 8, n. 2, p. 8-23, 2012.

FELKER, R. M. et al. Levantamento Do Perfil Ambiental Das Dos Produtores Rurais De São Valentim, Santa Maria - Rs. Desafio - online, Campo Grande, v. 1, n. 3, p. 1-14, 2013.

FERNANDES, N. D. S. et al. Avaliação parasitológica de hortaliças: da horta ao consumidor final. Saúde e Pesquisa, Maringá, v. 8, n. 2, p. 255-265, 2015. https://doi.org/10.17765/19831870.2015v8n2p255-265

FRIESTINO, J.; SILVA, O.; NASCIMENTO, M. Condições Sanitárias no Oeste de Santa Catarina: Construindo um diagnóstico das populações rurais e pequenas comunidades. Revista Brasileira de Ciências da Saúde, João Pessoa, v. 19, n. 2, p. 109-116, 2015. https://doi.org/10.4034/RBCS.2015.19.02.04

GARDIMAN JUNIOR, B. S. Qualidade da água de microbacias hidrográficas sob atividades silviculturais em Aracruz,ES. 2012. 121f. Dissertação (Mestrado em Ciências Florestais) - Universidade Federal do Espírito Santo, Jerônimo Monteiro. 2012.

GONÇALVES, B. V. Relações socioambientais na recuperação florestal da sub-bacia hidrográgica do Rio Poxim, Sergipe. 2013.120f. Dissertação (Mestrado em Desenvolvimento e Meio Ambiente) - Universidade Federal de Sergipe, São Cristovão. 2013. https://doi.org/10.5380/dma.v29i0.32327

GONÇALVES, B. V.; GOMES, L. J. Percepção ambiental de produtores rurais na recuperação florestal da sub-bacia hidrográfica do rio Poxim - Sergipe. Desenvolvimento e Meio Ambiente, Curitiba, v. 29, p. 127-138, 2014. https://doi.org/10.5380/dma.v29i0.32327

IBGE - Instituto Brasileiro de Geografia e Estatística. Lixo é queimado em $58 \%$ dos domicílios rurais. Sala de Imprensa. 2013. Disponível em: <https://agenciadenoticias.ibge.gov.br/agencia-sala-de-imprensa/2013-agencia-denoticias/releases/14122-asi-censo-2010-mais-da-metade-dos-emigrantes-brasileiros-saomulheres.html>

INCAPER - Instituto Capixaba De Pesquisa, Assistência Técnica e Extensão Rural. Guaçuí Planejamento e programação de ações. Espírito Santo: Instituto Capixaba de Pesquisa Assistência Técnica e Extensão Rural, 2011.

KOBIYMA, M.; MOTA, A. A.; CORSEUIL, C. W. Recursos hidrícos e saneamento. Curitiba: Organic Trading, 2008.

LOPES, F. B. et al. Mapa da qualidade das águas do rio Acaraú , pelo emprego do IQA geoprocessamento. Revista Ciência Agronômica, Fortaleza, v. 39, n. 3, p. 392-402, 2008.

MANOEL, L. DE O.; CARVALHO, S. L. DE. Qualidade do recurso hídrico de duas nascentes na microbacia do Córrego Caçula no município de Ilha Solteira-SP. Revista Científica ANAP Brasil, v. 6, n. 7, p. 151-166, 2013. https://doi.org/10.17271/19843240672013428

MAROTTA, H.; SANTOS, R. O.; ENRICH-PRAST, A. Limnological assessment: a tool for water conservation in the environmental-urban planning and management. Ambiente \& Sociedade, 
Campinas, v. $11, \quad$ n. $1, \quad$ p. $207-208,2008 . \quad$ https://doi.org/10.1590/S1414753X2008000100006

MARCATTI, B. A. Impacto do uso da terra e da estratificação ambiental no assentamento rural Florestan Fernandes sobre a qualidade do solo. 2014. 102f. Dissertação (Mestrado em Produção Vegetal) - Universidade Federal do Espírito Santo,Alegre. 2014.

MASTERS, N. et al. Escherichia coli virulence genes profile of surface waters as an indicator of water quality. Water Research, Dübendorf, v. 45, n. 19, p. 6321-6333, 2011. https://doi.org/10.1016/j.watres.2011.09.018

PEZZOPANE, J. E. M. et al. Agrometeorologia: aplicações para o Espírito Santo. Alegre, ES: CAUFES, 2012.

PIASENTIN, A. M. et al. Indice de Qualidade da Agua (IQA) do reservatorio Tanque Grande, Guarulhos (SP): Analise sazonal e efeitos do uso e ocupacao do solo. Geociencias, São Paulo, v. 28, n. 3, p. 305-317, 2009.

SANTOS, G. V. et al. Análise hidrológica e socioambiental da bacia hidrográfica do Córrego Romão dos Reis, Viçosa-MG. Revista Árvore, Viçosa, v. 31, n. 5, p. 931-940, 2007. https://doi.org/10.1590/S0100-67622007000500017

SANTOS, R. C. L. Caracterização e aspectos socioambiental da bacia Costeira do Sapucaia em Sergipe. 2016. Dissertação (Mestrado em Saúde e Ambiente) - Universidade Tiradentes, Aracaju. 2016.

SCHIMITZ, L. A. Proteção de fontes de água em unidades de produção e vida familiares (UPVFS) no Sudoeste do PAraná: uma análise das ações desenvolvidas pela ACESI/STR, GETERR/UNIOESTE e EMATER-PR. 2017. 258f. Dissertação (Mestrado em Geografia) Universidade Estadual do Oeste do Paraná, Francisco Beltrão. 2017.

SILVA, W. T. L. DA. Saneamento básico rural. $1^{\text {a }}$ ed. Brasília, DF: Embrapa Informação Tecnológica Coordenação, 2014.

SIMONATO, D. C. Questões ambientais, socioeconômicas e histórias de vida de assentados/as rurais do assentamento Estrela da llha no município de llha Solteira - SP. 2013. 177f. Dissertação (Agroecologia e Desenvolvimento Rural) - Universidade Federal de São Carlos, Araras. 2013.

SOUZA, A. C. et al. Perfil epidemiológico das parasitoses intestinais e avaliação dos fatores de risco em indivíduos residentes em um assentamento rural do Nordeste brasileiro. Revista Conexao UEPG, Ponta Grossa, v. 12, n. 1, p. 26-37, 2016. https://doi.org/10.5212/Rev.Conexao.v.12.i1.0002

SOUZA, A. P. A. B. Índice de qualidade da água em microbacias hidrográficas com diferentes coberturas vegetais, no sul do estado do Espírito Santo. 2011. Dissertação (Mestrado em Ciências Florestais) Universidade Federal do Espírito Santo, 2011.

SPERLING, M. Introdução à qualidade das águas e ao tratamento de esgotos. $3^{\text {a }}$ ed. Departamento de Engenharia Sanitária e Ambiental - UFMG, Belo Horizonte, 2005, 243 p.

TUNDISI, J. G. Recursos hídricos no futuro: problemas e soluções. Estudos Avançados,São Paulo, v. 22, n. 63, p. 7-16, 2008. https://doi.org/10.1590/S0103-40142008000200002

VIEIRA, L. R.; VIEIRA, L. R.; VESTENA, S. A questão do saneamento no espaço rural: uma abordagem ambiental em três localidades rurais no município de Nova Palma, RS. Revista Eletrônica em Gestão, Educação e Tecnologia Ambiental, v. 19, n. 1, p. 38-50, 2015.

VISSER, S. et al. Estudo da associação entre fatores socioambientais e prevalência de parasitose intestinal em área periférica da cidade de Manaus (AM, Brasil). Ciência \& Saúde Coletiva, Rio de Janeiro, v. 16, n. 8, p. 3481-3492, 2011. https://doi.org/10.1590/S1413$\underline{81232011000900016}$

Recebido em: 27/08/2019

Aceito para publicação em: 20/02/2020 